\title{
ENTRE O MODERNO E O AUTORITÁRIO, O LIBERAL E O CONSERVADOR: O PROJETO DE SOCIALIZAÇÃO POLÍTICO-IDEOLÓGICO CONTIDO NA DISCIPLINA ESTUDO DE PROBLEMAS BRASILEIROS*
}

\author{
Samara Lima Tavares Mancebo Lerner ${ }^{1}$
}

\begin{abstract}
RESUMO: Em 1969, foi tornada obrigatória a disciplina Estudo de Problemas Brasileiros (EPB). Voltada a alunos do ensino superior, a EPB foi criada com o propósito de preparar, moral e civicamente, os jovens para a defesa da democracia, dos valores espirituais e éticos da nacionalidade, e para a contribuição no desenvolvimento e na segurança nacionais. A tríade Deus-Pátria-Família e a Doutrina de Segurança Nacional constituíam o conteúdo da disciplina, que deveria funcionar como um instrumento de luta ideológica contra o movimento estudantil, a infiltração comunista e o suposto esfacelamento da moral cristá. Dentro desse contexto, este artigo buscará contribuir com os estudos que enfocam projetos de socialização política conduzidos pelo Estado, tomando como objeto de análise o projeto de socializaçáo contido na disciplina EPB.
\end{abstract}

Palavras-chave: Estudo de Problemas Brasileiros (EPB). Educação Moral e Cívica (EMC). Regime militar. Doutrina de Segurança Nacional (DSN).

\section{BETWEEN THE MODERN AND THE AUTHORITARIAN, THE LIBERAL AND THE CONSERVATIVE: THE POLITICAL-IDEOLOGICAL SOCIALIZATION PROJECT CONTAINED IN BRAZILIAN PROBLEMS STUDY SUBJECT}

\begin{abstract}
In 1969, the Brazilian Problems Study subject (Estudo de Problemas Brasileiros - EPB) was made compulsory. It was addressed to students in higher education with the purpose of morally and civically preparing youngsters to defend democracy, the ethical and spiritual values of nationality, and to foment national security and development. The God-Motherland-Family triad and the National Security Doctrine (Doutrina de Segurança Nacional - DSN) constituted the content of
\end{abstract}

\footnotetext{
*O artigo em questão baseia-se em dados coletados para elaboração de tese de doutoramento de Samara Lima Tavares Mancebo Lerner intitulada A Pós-Graduação em Estudos de Problemas Brasileiros na UERJ: uma reflexão sociológica sobre um projeto de socialização politica no Brasil. A tese foi realizada sob a orientaçấo e co-orientação respectiva dos professores doutores Helena Bomeny e Luiz Antônio Cunha, e defendida no Instituto de Ciências Sociais, da Universidade do Estado do Rio de Janeiro, em fevereiro de 2013.

${ }^{1}$ Pontifícia Universidade Católica do Rio de Janeiro (PUC-Rio), Departamento de Ciências Sociais.

E-mail: samaramancebo@gmail.com

DOI: 10.1590/ES0101-73302016166364
} 
EPB subject, which should work as an ideological struggle instrument against student movement, communist infiltration and the supposed disintegration of Christian morality. In this context, this article aims to contribute to studies that focus on political socialization projects conducted by the State, taking the socialization project contained in EPB subject as an object of analysis.

Keywords: Brazilian Problems Studies (EPB). Moral and Civic Education (EMC). Brazilian military regime. National Security Doctrine (DSN).

\title{
ENTRE MODERNE ET AUTORITAIRE, LIBÉRAL ET CONSERVATEUR: LE PROJET DE SOCIALISATION POLITICO-IDÉOLOGIQUE CONTENU DANS LE COURS «ÉTUDE DE PROBLÈMES BRÉSILIENS»
}

\begin{abstract}
RESUME: En 1969, le cours "Étude de Problèmes Brésiliens» (Estudo de Problemas Brasileiros - EPB) a été rendu obligatoire pour tous les élèves de l'enseignement supérieur. Sous la forme du cours «Éducation Morale et Civique» (Educação Moral e Cívica - EMC), le cours EPB avait pour but de préparer les jeunes sur le plan moral et civique afin de défendre la démocratie, les valeurs spirituelles et éthiques de la nationalité brésilienne et de contribuer au développement du pays et à la sécurité nationale. La triade Dieu-Patrie-Famille et la Doctrine de Sécurité Nationale (Doutrina de Segurança Nacional - DSN) constituaient le corpus de la discipline, qui devait fonctionner comme un instrument de lutte idéologique contre les mouvements étudiants, l'infiltration communiste et le supposé délitement de la morale chrétienne. Dans ce contexte, le présent article cherche à contribuer aux études autour des projets de socialisation politique menés par l'État, en choisissant comme objet d'analyse le projet de socialisation inhérent au cours EPB.
\end{abstract}

Mots-clés: Étude de Problèmes Brésiliens (EPB), Éducation Morale et Civique (EMC), Régime Militaire Brésilien, Doctrine de Sécurité Nationale (DSN).

\section{Introdução}

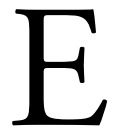

m 1969, auge do regime militar no Brasil, foi tornada obrigatória a prática e a disciplina de Estudo de Problemas Brasileiros (EPB). Como uma forma da Educação Moral e Cívica (EMC), o EPB deveria ser ministrado a alunos do ensino superior com o propósito de preparar moral e civicamente os jovens para, entre outros objetivos, defender a democracia, os valores espirituais e éticos da nacionalidade, e contribuir para a segurança e o desenvolvimento nacionais. A tríade Deus-Pátria-Família e a Doutrina de Segurança Nacional (DSN) constituíram o conteúdo da disciplina, fazendo frente aos inimigos que deveriam ser vencidos por meio de sua socialização: a ameaça comunista, o movimento 
estudantil e o suposto esfacelamento dos valores morais cristãos. Dentro desse contexto, este artigo buscará contribuir com os estudos que enfocam projetos de socialização política conduzidos pelo Estado no Brasil, tomando como objeto de estudo o projeto de socialização político-ideológico contido na disciplina EPB. Remontar a tal projeto exigirá a ênfase no conteúdo de EPB, seus propósitos, seus antecedentes e suas bases de sustentação político-ideológicas. Para isso, serão analisados os documentos pertinentes ao EPB e à EMC, assim como a bibliografia relacionada ao tema. O recorte temporal do trabalho refere-se aos primeiros anos de vigência formal da disciplina, uma vez que serão abordados documentos do final dos anos 1960 e início dos 1970 que visavam à realização do projeto de EPB.

São fartos os trabalhos sobre a EMC no Brasil, e mostra-se consensual, nesses estudos, a compreensão dessa disciplina como instrumento autoritário, prenhe de um projeto político-pedagógico bem definido, voltado à socialização política de crianças e jovens (BOMENY, 1981; CUNHA, 2007a; 2007b; FILGUEIRAS, 2006; JOSGRILBERT, 1998; LEMOS, 2011; OLIVEIRA, 1982; para citar alguns). Mais escassos, no entanto, são os trabalhos desenvolvidos sobre o EPB. Luiz Antonio Cunha (2010; 2012) e Mancebo-Lerner (2013) ofereceram contribuiçóes recentes nesse campo de estudo, que serão de grande valia para este artigo.

Como uma forma da EMC em nível superior de ensino, o EPB também possuía um projeto político-pedagógico bem definido e compartilhava o mesmo princípio autoritário e conservador daquela disciplina, sendo direcionado, no entanto, para um público específico: o de jovens universitários. Expressão de grande resistência ao regime dos militares, de apoio a políticas reformistas e de aproximação com ideologias de esquerda, os estudantes universitários - sobretudo aqueles associados ao movimento estudantil - tornaram-se alvo preferencial da repressáo militar (CANCIAN, 2010; HAYASHI; VICINO, 2007). Tornou-se necessário, portanto, criar instrumentos capazes de conter sua movimentação, para além dos recursos repressivos já utilizados. $\mathrm{O}$ EPB assumiu claramente tal função estratégica ${ }^{1}$.

Assim como o próprio regime, o EPB recebeu apoio de distintos segmentos da sociedade civil e aliou, em seu projeto político, o pensamento reacionário e o catolicismo conservador a diretrizes liberal-modernizantes (CUNHA, 2009; MOTTA, 2002; 2014). O temor às ideologias de esquerda (em especial ao comunismo) e o arrefecimento dos valores morais (que estariam desestruturando as famílias tradicionais brasileiras e impondo riscos à segurança e ao desenvolvimento nacional) figuravam entre as maiores preocupaçôes do regime e estavam na base dos problemas brasileiros a serem solucionados no país. Tais problemas, assim como as diretrizes para seu equacionamento, constituíam a Doutrina de Segurança Nacional (DSN), elaborada pela Escola Superior de Guerra (ESG). Pode-se dizer que a DSN respondeu tanto pela sustentação ideológica do regime quanto pela fundamentação do EPB. Tal aproximação entre a DSN e o EPB é tomada, neste artigo, como um sinal indisfarçável do conteúdo doutrinário da disciplina, de seu 
caráter instrumental, bem como de sua função socializadora de valores, ideias e condutas caros ao regime militar. Valores, ideias e condutas que, juntos, como a própria DSN permite vislumbrar, deram vida a um projeto de socialização, ao mesmo tempo liberal e conservador, modernizante e autoritário.

Voltar os olhos para o EPB, portanto, mostra-se importante para contribuir tanto com os estudos que enfatizam projetos de socialização política conduzidos pelo Estado, por meio do processo educacional, quanto para ampliar a compreensão sobre o próprio regime militar. Ao remontar ao conteúdo do EPB e atentar para seus propósitos e suas bases de sustentação político-ideológicas, destacarei elementos-chave para a compreensão da ideologia que deu sustentação ao golpe de 1964 e ao regime que o sucedeu, assim como valores e princípios que orientaram suas açóes desenvolvimentistas, mas repressivas; modernas, mas conservadoras e autoritárias.

O foco deste artigo está no projeto e não no processo de socializaçáo política envolvido com o EPB. A análise do processo de socialização política implicaria dar conta da própria formação (ou não) de mentalidades e hábitos comportamentais concernentes ao conteúdo político-ideológico da disciplina. Algo desse gênero foi realizado pela socióloga Helena Bomeny, em sua dissertação de Mestrado (1981)². Diferentemente da pesquisa realizada por Bomeny (1981), o objeto deste artigo não é o processo de "interiorização de valores", os "efeitos" da socialização política, mas o projeto que envolve o conteúdo político e ideológico do EPB ministrado aos estudantes-alvo da disciplina. Ao tomar tal projeto de socialização como objeto, a este artigo interessa mapear $o$ que se queria socializar com $\mathrm{EPB}$, por que e para quem.

Tal mapeamento será feito em duas seções. Na primeira, o EPB será contextualizado, e sua função instrumental e estratégica para o regime será caracterizada. Caracterizar o EPB implicará abordar o estudo da moral e do civismo no Brasil, sua relação histórica com os campos militar e religioso ${ }^{3}$, além dos valores, dos propósitos e das ameaças envolvidos em sua (re)criaçáo, no final dos anos 1960. Na segunda seção, a preocupação do artigo recairá sobre a DSN, da ESG, também fundamental para a caracterização do EPB. As duas seções, portanto, complementam-se e permitem vislumbrar a ambiguidade central que constituiu tanto o projeto de socialização contido no EPB quanto o próprio regime que foi berço para seu desenvolvimento.

\section{Contextualizando o estudo de problemas brasileiros e delimitando seu caráter estratégico para o regime militar}

A imagem da Educação Moral e Cívica, no Brasil, costuma trazer consigo a imagem do próprio período militar, tal seu caráter autoritário e o fato de ter sido normatizada durante esse regime de governo. No entanto, há que se ressaltar que o estudo da moral e do civismo não é especificidade sua. Desde a Proclamação da República, quando se começou a pensar na educação como importante instrumento 
para a formação de cidadãos e promoção da ordem e do progresso, o ensino da moral e/ou do civismo passou a ser estimulado nas escolas e a integrar o currículo escolar, ora como disciplina, ora como prática educativa, ora de forma obrigatória, ora facultativa, ora associado à moral religiosa, ora influenciado pela doutrina positivista, ora pela Doutrina de Segurança Nacional. Tais transformaçóes na configuração assumida pelo ensino da moral e cívica no currículo escolar, no correr do século XX, guardam forte relação com o poder de influência dos campos religioso e militar sobre o educacional, e com a própria configuração do cenário político. Quanto mais instável o cenário, mais requisitado era o ensino da educação moral e cívica.

Em momentos de grande instabilidade social e política, como ocorreu na Era Vargas e no regime militar, a educação foi mais fortemente chamada a atuar como estratégica para conformar os educandos a um determinado projeto político-ideológico que fosse capaz de moldar o cidadão disciplinado e ordeiro, que não viesse a representar ameaças à ordem e à segurança nacional. Foi a partir desse pano de fundo, portanto, que a EMC e o EPB foram (re)criados (1969) e normatizados (1971), durante o regime militar.

Ao longo do século XX, o ensino da moral e cívica assumiu variadas formas: Instrução Cívica (1911), Instrução Moral e Cívica (1925), Educação Cívica (1937) e Educação Moral e Cívica - primeiro na forma de prática educativa (1942) e, posteriormente, também como disciplina obrigatória no currículo (1969). A cada uma dessas fases, a configuração do ensino da moral e do civismo respondeu diferenciadamente a interesses dos campos militar e religioso que, de forma separada ou associada, mostraram-se hábeis em se projetar sobre o campo educacional. A relação da EMC com os referidos campos desenvolveu-se, portanto, dentro de um vai e vem histórico e político que marcou definitivamente a função estratégica e ideológica da disciplina, assim como seu conteúdo, em cada um dos períodos referidos. Desse modo, o que socializar, por que e para quem devem ser compreendidos à luz dessa relação e do respectivo cenário político.

Se o ensino da moral e do civismo não pode, então, ser tomado como especificidade do regime militar, foi certamente nesse período em que se viu mais requisitado e doutrinariamente definido, tendo assumido função estratégica dentro do governo. Em 1969, auge da fase mais repressiva do regime e de maior organização do movimento estudantil, a Educação Moral e Cívica (re)nasceu por meio do Decreto-Lei no 869 , comprometida com um projeto político-pedagógico voltado a enfrentar "os perigos do neutralismo" que se faziam "sentir concretamente no mundo estudantil” (Bomeny, 1981, p. 44). Não à toa, a EMC foi tornada obrigatória em todos os níveis de ensino, passando a assumir a forma de EPB no ensino superior. Como disciplina ministrada em nível superior de ensino, o EPB voltou-se exclusivamente para a juventude universitária e expressou, em seu conteúdo, um vigoroso consenso que uniu civis e militares nos anos 1960: o da necessidade de defender o Brasil do comunismo. Nesse sentido, pode-se dizer que o EPB assumiu estrategica- 
mente uma função profilática dentro do regime: a de afastar a juventude da "ideologia malsâ" por meio da socialização em valores, ideias e comportamentos capazes de regenerar a moral cristã e a obediência a Deus, à Pátria e à Família. Tais valores, ideias e comportamentos podem ser depreendidos das finalidades da disciplina, apresentadas no Decreto-Lei no 869 (BRASIL, 1969), a saber:

a) a defesa do princípio democrático, através da preservação do espírito religioso, da dignidade da pessoa humana e do amor à liberdade com responsabilidade, sob a inspiração de Deus;

b) a preservação, o fortalecimento e a projeção dos valores espirituais e éticos da nacionalidade;

c) o fortalecimento da unidade nacional e do sentimento de solidariedade humana;

d) o culto à pátria, aos seus símbolos, tradiçôes, instituições e grandes vultos de sua história;

e) o aprimoramento do caráter, com apoio na moral, na dedicação à família e à comunidade;

f) a compreensão dos direitos e deveres dos brasileiros e o conhecimento da organizaçáo sócio-político-econômica do país;

g) o preparo do cidadáo para o exercício das atividades cívicas, com fundamento na moral, no patriotismo e na ação construtiva visando ao bem comum;

h) o culto da obediência à lei, da fidelidade ao trabalho e da interação na comunidade.

Como pôde ser visto anteriormente, o ensino de EPB tinha por finalidade promover o desenvolvimento de hábitos democráticos e a formação da consciência cívica nos alunos, com fundamento na moral cristã-católica. Segundo Mancebo-Lerner (2013, p. 58), "tais hábitos democráticos e a consciência cívica seriam resultado da disseminação sistemática de discursos enaltecedores da pátria, dos símbolos nacionais e da obediência ao Estado e a Deus, na forma de cumprimento de deveres e da ação voltada para o bem comum". Tais tradiçóes deveriam ser valorizadas para fazer frente ao comunismo que, supostamente, estaria desviando os jovens do caminho da moral, dos bons costumes e corroendo as bases da sociedade brasileira. Além da preocupação com a segurança nacional, fazia-se necessário também preparar os jovens para contribuir com o desenvolvimento do Brasil. Nesse sentido, mostrava-se fundamental a socialização em conhecimentos pertinentes à organização sociopolítica e econômica do país, de modo a preparar os jovens tanto para equacionar os problemas nacionais, caracterizados como obstáculos ao desenvolvimento, como também a prepará-los adequadamente - e ideologicamente — para assumir postos de liderança no Estado e no mercado de trabalho. O EPB deveria contribuir com tal formação, controlando os jovens em um primeiro momento (em favor da ordem) e 
formando-os moral e politicamente para garantir o desenvolvimento futuro do país (fomentando o progresso, portanto).

A luta contra o comunismo e as ideologias de esquerda, durante o regime militar, apresentou-se sempre em nome da defesa da liberdade. Mas uma liberdade que, como pode ser observado no Decreto-Lei $n^{\circ}$. 869, deveria ser gozada com responsabilidade. Tal adjetivação funcionava como uma tentativa de disfarçar seu esvaziamento político e axiológico, tornando-a um mero instrumento para assegurar a ordem, e não um valor a ser resguardado para a legitimidade do próprio liberalismo político e da democracia. O mesmo pode ser dito do uso feito dos termos democracia e cidadania no referido decreto e nos demais documentos relacionados ao EPB.

O termo cidadania é utilizado no Decreto-Lei no ${ }^{\circ}$.869/69 em associação à "compreensão de direitos e deveres" e à finalidade de formar cidadáos "para o exercício das atividades cívicas" (BRASIL, 1969), desde que essas tivessem fundamento na moral e no patriotismo. Interessa, no entanto, chamar a atenção para tal noção de cidadania e atentar para a prática efetiva da restrição de direitos civis e políticos durante o regime militar. A criaçáo de uma disciplina para defesa da democracia e dos direitos de cidadania, quando essa, em verdade, tomava como um de seus objetivos controlar a participação política da juventude universitária, expressa muito claramente o caráter instrumental e ambíguo do EPB.

Nesse mesmo sentido, a menção à democracia e sua defesa - frequentemente presente nos documentos sobre $\mathrm{EPB}$ - pode ser notada, como se pode ver, desprovida do respeito aos direitos de cidadania, mas claramente associada à resistência ao comunismo e à respectiva obediência a Deus, à Pátria e à Família. Os "princípios democráticos" que constituíam o conteúdo de EPB possuíam, portanto, um caráter instrumental e axiologicamente vazio, em atenção ao próprio projeto político-ideológico que se queria socializar.

A menção a Deus nas finalidades da disciplina não deve ser vista com surpresa. Para além da indisfarçada e tradicional projeção do campo religioso sobre o educacional e do uso instrumental dos valores religiosos para o controle social, até mesmo nas Constituiçóes Federais do Brasil — um Estado Laico — a proteção de Deus era invocada. Ademais, sendo o comunismo ateu, entendia-se que seu enfrentamento não poderia prescindir da moral embasada na tradiçáo católica e tendo Deus como fundamento.

Se o Decreto-Lei no 869/69 deixou à mostra a defesa dos valores morais cristãos, do culto à família e à nacionalidade, o Parecer no. 94/71, que normatizou a EMC e o EPB, ao apresentar seu currículo, expressou claramente a influência da DSN no conteúdo das referidas disciplinas. Ao socializar os jovens na DSN, sustenta-se que o EPB assumia a funçáo de reproduzir a ideologia do regime, reforçando, por sua vez, seu caráter instrumental e estratégico para os militares. Tal fundamentação doutrinária será abordada agora, na apresentação da DSN e do currículo do EPB, determinado pelo Conselho Federal de Educação (CFE), em 1971. 


\title{
A Doutrina de Segurança Nacional e o programa de estudo de problemas brasileiros
}

Uma importante instituição para o campo militar foi criada, no Brasil, no final dos anos 1940: a ESG. Identificada como um "centro de altos estudos e pesquisas relacionados com a Política Nacional” (ESG, 1974), a ESG destinava-se a desenvolver os conhecimentos necessários ao exercício das funções de direção e planejamento da Segurança Nacional por meio da realização de pesquisas e ministraçáo de cursos, como o Curso Superior de Guerra (CSG), por exemplo (ESG, 1973). Como aparelho de sustentação ideológica do campo militar e, posteriormente, do regime instaurado em 1964, a ESG se prontificou a criar importantes instrumentos para socialização de sua doutrina. Pode-se tomar o EPB como um desses instrumentos, visto ter sido criado com apoio da instituição, com base em sua DSN e a partir de um grupo de trabalho de sua Associação dos Diplomados da Escola Superior de Guerra (ADESG) (CUNHA, 2012).

Criada pela ESG, a DSN dizia respeito a um constructo político ideológico, cuja elaboração visava contribuir para construção de um projeto de Nação para o Brasil, prenhe de teorias desenvolvimentistas, mas conservadoras em seus valores e na luta contra o comunismo. Elaborada no contexto da guerra fria, a DSN constituiu-se a partir da luta contra o comunismo e foi determinante para a formulação metodológico-doutrinária dos cursos desenvolvidos na Escola. Além disso, como aponta Sepúlveda (2011, p. 124), representou o elo que faltava entre civis e militares ao articular "de forma coerente, segurança com o desenvolvimento econômico". Ou seja, a DSN foi hábil em unir os interesses de vários campos e setores da sociedade em torno das questóes que definia como sendo fundamentais para o desenvolvimento do país: o alcance da segurança nacional, a valorização da moral cristã, além do culto à pátria e à família. Deve-se ressaltar, no entanto, que tais valores constituintes da DSN não foram criados por ela,

\begin{abstract}
mas reificados a partir das noçóes de desenvolvimento e segurança nacional. Eram valores incrustados nas tradiçóes nacionais defendidos pelo campo religioso na medida em que assegurava seu fortalecimento; pelo campo político na medida em que contribuía para o disciplinamento e controle do povo; pelo empresariado que adequava esse controle e a recusa ao comunismo aos seus interesses capitalistas... (MANCEBO-LERNER, 2013, p. 53-54).
\end{abstract}

Do consenso em torno da articulaçáo desses elementos, portanto, proveio a legitimação social para o golpe e as bases de sustentação ideológica para o estabelecimento e a posterior manutenção do regime militar. Proveio também a organização do conteúdo ideológico do EPB, que interessa mais detidamente a este artigo. 
Tal como foi definida por Borges (2009) e Santos (2010), a DSN era, simultaneamente, uma doutrina de açáo política e a manifestação de uma ideologia, orientando-se a partir das noçōes de guerra interna e permanente contra o comunismo. Objetivamente, a DSN desenvolveu-se a partir de quatro conceitos principais, todos presentes no programa do EPB: os Objetivos Nacionais, o Poder Nacional, a Estratégia Nacional e a Segurança Nacional. Para a ESG, cabia ao Estado fazer uso do Poder Nacional para o alcance e a manutenção dos Objetivos Nacionais - principal função do Estado e fundamental para a própria garantia da Segurança Nacional. Para exercer o Poder Nacional, por sua vez, o Estado deveria fazer uso de um instrumento específico, a Estratégia Nacional. Os referidos objetivos diziam respeito à integridade territorial, à integração nacional, à democracia, ao progresso, à soberania e à paz social. Todos eles, sem exceção, integravam o programa do EPB. Por fim, a Segurança Nacional, razáo de existência da DSN, referia-se ao componente doutrinário que permitiria ao Estado traçar seus objetivos, as estratégias para alcançá-los, bem como estabelecer a justificativa para seu poder (Camargo, 1979).

Diante do clima de guerra que envolveu a criação da ESG e a formulação de sua doutrina, a moral ocupou lugar de destaque para fazer frente ao inimigo que ameaçava a segurança nacional. Nos anos 1960, com a eclosão da Revolução Cubana (1959), a (re)atualizaçáo da ameaça comunista e a maior organização dos movimentos operário e estudantil, a preocupação da ESG com a moral se viu reforçada de tal maneira que a moral foi incorporada aos instrumentos necessários para o alcance dos Objetivos Nacionais (Oliveira, 1982). Daí a necessidade de tornar obrigatório o ensino de EMC/EPB, sobretudo o EPB, porquanto voltado para a juventude universitária que, segundo os militares, mostrava-se mais suscetível à ameaça comunista e ao proselitismo das lideranças estudantis. Um bom exemplo de como a juventude esteve, durante o regime militar, no centro dos problemas brasileiros a serem enfrentados e de como esse enfrentamento deveria ocorrer pode ser visto em um discurso proferido na ESG em 1972, por seu entáo comandante, o general João Bina Machado. No referido discurso, a juventude era mencionada como um "problema brasileiro de Recursos Humanos" e "assunto de inequívoca sobrevivência nacional" (ESG, 1972, p. 4-5). Para o comandante da ESG, tal problema (moral) deveria ser enfrentado mediante o emprego de uma "arma psicológica (ou seja, a influenciaçâao psicológica) através dos mesmos e conhecidos veículos e técnicas de comunicação social da vida cotidiana, particularmente os de massa, visando a criar, subliminarmente, comportamentos adequados nos grupos adversos eleitos como alvo" (ESG, 1972, p. 5).

Para o comandante, a ESG deveria "considerar tais fatos com a devida primazia em sua estratégia de planejamento da Segurança Nacional” (ESG, 1972, p. 5). Náo por acaso, o projeto de EBP foi criado com apoio de esguianos (civis e militares) e fundamentado na doutrina da referida Escola. 
Como abordado anteriormente, a EMC e o EPB foram tornados disciplina e prática educativa obrigatórias por meio do Decreto-Lei no ${ }^{\circ}$. 869/69. Quase dois anos depois, o referido decreto foi regulamentado pelo Decreto $\mathrm{n}^{\circ}$. 68.065 (BRASIL, 1971a) e, um mês mais tarde, o Parecer no. 94/71, do Conselho Federal de Educação, normatizou o ensino e o programa das referidas disciplinas. Como não poderia deixar de ser, dada a determinação dos referidos documentos e o contexto político autoritário vigente, as instituiçōes educacionais brasileiras, fossem públicas ou privadas, viram-se obrigadas a ministrar o EPB. O contexto político não deixou muita saída aos renitentes, o que não quer dizer que não tenha havido resistência à obrigatoriedade do EPB. Houve, mas não foi unânime, tampouco organizada. E careciam de organização por força da própria repressão impetrada pelo regime. Por outro lado, existiram instituiçóes de ensino que se mostraram afins à adoção do $\mathrm{EPB}$ em seu currículo programático, muitas vezes compartilhando da necessidade moral de sua disseminação. Isso porque a ideologia nacional-desenvolvimentista e democrático-cristá que constituía a DSN, e que estava impregnada no $\mathrm{EPB}$, não se restringia aos círculos militares, mas era compartilhada também por diversos setores civis da sociedade (reacionários, conservadores e religiosos, em maior medida). Além das afinidades ideológicas que marcaram a relação entre algumas instituiçóes de ensino e o regime militar, outras instituiçōes preferiram dissimular tais afinidades, adotando prontamente e sem resistência o ensino de EPB para evitar sançōes por parte do governo. Tais sançóes poderiam vir na forma de jubilações de professores, presença de interventores nas instituições, limitação do repasse de verbas etc. De acordo com o grau de aprovação ou resistência ao ensino de EPB, cada instituição fez adequações ao programa do CFE, adotando-o integralmente - como foi o caso da Universidade do Estado do Rio de Janeiro (UERJ) (MANCEBO-LERNER, 2013) —, ou parcialmente - como ocorreu na Universidade Federal do Rio de Janeiro (UFRJ) (CUNHA, 2012). Nesse último caso, foram retirados do programa (como sinal de resistência) justamente os conteúdos que, como apontou Cunha (2012, p. 202), "expressavam, incontornavelmente, a doutrina da Escola Superior de Guerra".

O referido Parecer $n^{\circ} .94$ do CFE, que normatizou o ensino de EPB, além de ter apresentado um programa para o ensino da disciplina, tratou de dispor sobre questóes práticas como, por exemplo, o número de horas necessárias ao cumprimento do programa e a forma como a disciplina deveria entrar no currículo universitário, se condensada em uma ou mais disciplinas (BRASIL, 1971b). No caso da UERJ, para citar um exemplo, o conteúdo programático da disciplina foi dividido em dois semestres e ministrado sob a forma de EPB I e EPB II (MANCEBO-LERNER, 2013). O importante, segundo o próprio documento, era que o programa estipulado fosse cumprido e que ensino de EPB ocorresse sem prejuízo de outras atividades culturais.

Quanto ao programa de EPB, o CFE estabeleceu seis unidades a partir das quais o ensino da disciplina deveria ser desenvolvido: 
- $\quad$ Unidade I - Panorama Geral da Realidade Brasileira;

- $\quad$ Unidade II - Problemas Morfológicos;

- $\quad$ Unidade III - Problemas de Desenvolvimento Econômico;

- Unidade IV - Problemas Socioeconômicos;

- Unidade V - Problemas políticos; e

- $\quad$ Unidade VI - Segurança Nacional (BRASIL, 1971b).

A unidade I, Panorama Geral da Realidade Brasileira, compreendia as características geopolíticas do país, a formação étnica e cultural do povo brasileiro, suas instituiçóes, bem como questóes relativas à ação do homem na comunidade, à estratificação e à mobilidade social. A unidade II, intitulada Problemas Morfológicos, abarcava uma análise sobre as estruturas sociais, econômicas e políticas do Brasil (o que incluía tratar das características da democracia no Brasil), e sobre a estrutura dos poderes legislativo, executivo e judiciário. A unidade III, que diz respeito aos Problemas de Desenvolvimento Econômico, compreendia o estudo de temas como riqueza nacional, povoamento, desenvolvimento industrial e comercial, disparidades regionais, integração econômica, política monetária, trabalho, previdência social, mercado de capitais e problemas relativos à Amazônia, ao Nordeste brasileiro, à reforma agrária, ao transporte e à questão energética. A IV unidade, relativa aos Problemas Socioeconômicos, referia-se a questóes como habitação, saúde, saneamento básico, educação, comunicação social, arte, cultura, urbanização e, ainda, o papel da ciência, da tecnologia, das empresas e das Forças Armadas no processo de desenvolvimento socioeconômico. A unidade V, chamada Problemas Politicos, enfocava questóes como filosofia e ideologia políticas, poder nacional e suas expressóes, representação popular, partidos políticos, política econômica, social e externa, e aquelas relativas aos organismos internacionais como a Organização das Naçóes Unidas e a Organização dos Estados Americanos, e problemas geopolíticos que incluíam a ocupação do solo e limites territoriais. Por fim, a unidade VI, Segurança Nacional, compreendia os temas da segurança nacional interna e externa, da guerra revolucionária, das Forças Armadas e a questão do "estabelecimento de uma doutrina e formulação de uma política de segurança nacional - Conselho de Segurança Nacional — Estado Maior das Forças Armadas — Escola Superior de Guerra” (BRASIL, 1972).

As duas últimas unidades, que tratavam dos problemas políticos e da segurança nacional, eram aquelas que mais diretamente guardavam afinidade com o conteúdo da DSN. E como destacou Cunha (2012), foram justamente essas duas unidades que constituíram as bases doutrinárias do EPB.

Todos os temas mencionados, que cortam as referidas unidades, aludem aos chamados problemas nacionais que deveriam ser conhecidos para, posteriormente, serem equacionados em prol do desenvolvimento e segurança nacionais. 
Apesar de o Parecer no 94/71 expressar mais claramente a aproximação do EPB com a ESG e sua DSN, tal afinidade já se apresentava no próprio Decreto-Lei $\mathrm{n}^{\circ}$. 869. Isso porque parte do texto incorporado ao referido decreto, no que se refere às diretrizes para ensino de EMC/EPB, proveio de um anteprojeto de lei preparado, em 1967, por um grupo de trabalho da ADESG. Tal anteprojeto requeria a implantação, em caráter obrigatório, da disciplina EMC em todos os sistemas e níveis de ensino no Brasil. Embora não fosse a primeira proposta de inclusão de EMC/EPB no currículo escolar, essa da ADESG relacionava diretamente o ensino da EMC ao problema da segurança nacional (LEMOS, 2011). Havia claramente, nessa proposta, uma tentativa de instrumentalização da EMC/EPB, no sentido de corrigir as deficiências na formação moral e cívica dos jovens - que os levaria a atuar no movimento estudantil, por exemplo - para garantir a segurança interna do país.

O anteprojeto de lei da ADESG, por sua vez, recebeu clara influência da exposição de motivos 180-RP enviada ao Presidente da República, em 1965, pelo então Ministro da Guerra, o general Costa e Silva. Nela, o general apontou a necessidade de revisar a LDB-61, posto que suas diretrizes "neutras" não davam mais conta de enfrentar os problemas sociais que se mostravam à educação. A crítica à neutralidade ideológica do currículo pautava-se no entendimento de que a educação deveria se envolver na "guerra revolucionária" contra o comunismo e contra a fraqueza moral que atingia a conduta da juventude. Segundo Costa e Silva, no documento Exposição de motivos $n^{\circ} 180$ - RP/1965, diante da incapacidade das famílias modernas de cuidarem da formação moral de seus filhos, a escola precisaria tomar para si essa função e "reconduzir a juventude brasileira aos caminhos do civismo e do sadio patriotismo" (COSTA E SILVA, 1965 apud Lemos, 2011, p. 57). $\mathrm{O}$ instrumento para essa reconduçáo seria justamente o ensino de EMC/EPB.

Para Bomeny (1981), a exposição de motivos no 180-RP representa prova contundente da instrumentalização do ensino da Educação Moral e Cívica para frear a propagação da ideologia comunista. Segundo a socióloga, ficou expresso nessa exposição a função de "escudo protetor" que deveria assumir o ensino da EMC. Seguindo na mesma linha, Cunha (2009) argumentou que tal instrumentalização, claramente explicitada nas finalidades da disciplina, expressou uma "sólida fusão do pensamento reacionário, do catolicismo conservador e da doutrina de segurança nacional, conforme era concebida pela ESG” (Cunha, 2009, p. 8).

\section{Considerações finais}

Ao longo do artigo, pôde-se observar que, assim como o próprio regime militar, o EPB nasceu marcado por uma contradição central, articulando em seu projeto de socializaçáo os dois grandes impulsos do regime instaurado em 1964: um impulso liberal-modernizante e outro autoritário-conservador (MOTTA, 2014). 
O impulso modernizante concentrava-se na perspectiva econômica, cujo foco estava no crescimento econômico e na aceleração da industrialização. Tal impulso não somente fazia parte do currículo de EPB como a disciplina se prestava à formação de profissionais qualificados para contribuir com o desenvolvimento econômico e social do país. Como também foi sinalizado, o projeto de Nação veiculado pela DSN da ESG enfatizava claramente a necessidade de modernizar o Brasil, o que, por sua vez, significava promover o desenvolvimento socioeconômico, por um lado, e garantir a segurança nacional, por outro. O EPB refletiu tais influências ao tomar como um de seus objetivos o conhecimento dos problemas nacionais e seu respectivo equacionamento para o alcance do desenvolvimento e da segurança nacional.

O impulso liberal foi contemplado por meio da valorização — ainda que formal - do princípio democrático, e da liberdade política e econômica. Os referidos decretos e pareceres que criaram e normatizaram o ensino da disciplina demonstram claramente essa valorização.

O impulso autoritário-conservador visava, por um lado, manter os segmentos subalternos e os atores políticos excluídos da cena política e cultural e, por outro, combater as ideias e os agentes da esquerda por meio da socialização em valores tradicionais enaltecedores da pátria, da família e da religião católica (MOTTA, 2014). A associação do impulso liberal ao autoritário-conservador explica a presença meramente formal dos termos democracia, liberdade e cidadania no conteúdo de EPB. Além disso, chama atençáo para a necessidade do controle moral da juventude para a defesa da democracia. Essa, por sua vez, andava pari passu com o alcance da segurança nacional, posto que o inimigo que impunha riscos à segurança nacional era o mesmo que precisava ser enfrentado pela democracia: o comunismo.

Pode-se dizer que o grande elemento (retórico) articulador de todos esses impulsos no conteúdo do EPB foi o comunismo. A partir da luta contra a infiltração comunista, pode-se delimitar para quem o EPB estava voltado, o porquê de sua criação e $o$ que precisava ser socializado por meio de seu ensino. A associação da moral católica e da DSN em um mesmo programa de disciplina expressava, simultaneamente, a fragilidade do campo educacional no Brasil, que permitia sua projeção por outros campos, e a importância desses elementos para municiar a luta contra o comunismo.

O enfrentamento do "perigo vermelho" (MOTTA, 2002) mostrava-se necessário em tempos de forte e intensa articulação do movimento estudantil comandado, especialmente, por líderes da esquerda católica e de comunistas. A aproximação da ideologia comunista trazia preocupaçóes imediatas e futuras aos militares e aos civis que os apoiavam: em um primeiro momento, preocupavam-se com a juventude universitária, tida como alvo fácil do comunismo; em um segundo, como os próprios centros universitários, que, tidos como locus de mobilização esquerdista, ameaçavam a formação dos futuros dirigentes econômicos, e da elite intelectual e política do país (MOTTA, 2014). 
Nesse sentido, o EPB teria nascido para afastar a juventude do perigo comunista que impunha riscos à democracia, à segurança e ao desenvolvimento nacionais. Para tal, precisava, simultaneamente, fortalecer nos jovens os valores da pátria, da família e da moral fundamentada na tradição católica. Para além de controlar a ação política da juventude universitária, importava também socializá-la nos principais problemas nacionais e nos meios necessários para equacioná-los, visto que só assim se modernizaria o país. Tais problemas e meios constituíam a DSN.

A união da DSN aos valores enaltecedores da pátria, da família e da religião, portanto, compôs o projeto de socialização político-ideológico contido no $\mathrm{EPB}$, e construiu tanto a necessidade moral de sua obrigatoriedade, quanto delimitou o conteúdo que deveria ser socializado e o meio pelo qual essa socialização deveria ocorrer: o universitário - ponto de partida do impulso modernizador tanto por sua capacidade de formar profissionais qualificados, líderes e dirigentes, como também por ser capaz de incutir valores nos jovens. Somente por meio da socialização em valores, propósito de $\mathrm{EPB}$, seria possível, como apropriadamente apontou Motta (2014, p. 185), "disputar com a esquerda a mente e o coração dos jovens".

\section{Notas}

1. Vale destacar que o Projeto Rondon também assumiu função estratégica para o regime militar em sua luta para controlar a participação política da juventude universitária e fomentar o desenvolvimento nacional. Idealizado na UERJ e desenvolvido em conjunto com militares, a partir de 1967, o Projeto Rondon se tornou o projeto de expansão mais conhecido do país. Para mais informaçốes, consultar Mancebo-Lerner (2013).

2. Em sua dissertação, Bomeny (1981) tomou como objeto de análise o processo de socialização política envolvido no ensino de EMC, implementado pela Fundação Maranhense de Televisão Educativa. Nesse sentido, seu interesse estava em apreender em que medida as noçóes políticas contidas no ensino de EPB influíam na visão de mundo dos alunos, na forma como percebiam os processos socais.

3. O conceito de campo utilizado neste artigo remete à definição de Bourdieu (2004), para quem o campo representa um universo autônomo, visto que portador e construtor de regras e normas a partir das quais os agentes que o compõem e dele participam criam, reproduzem e disseminam todas as formas simbólicas produzidas que, por sua vez, constituem e orientam o próprio campo e a forma como os agentes devem agir dentro dele. Neste artigo, endosso a tese de Sepúlveda (2011), para quem o fato do campo educacional ter exercido papel secundário até a República, e de ter se caracterizado como um campo fraco, com pouca autonomia, favoreceu o processo de projeção de outros campos sobre ele, sobretudo o religioso e o militar. Sustenta-se que tal projeção — que remete à presença de elementos de um campo sobre outro - foi determinante para construção do projeto político-ideológico contido na disciplina de EPB. 


\section{Referências}

BOMENY, H.M.B. Paraíso tropical: a ideologia do civismo na TVE do Maranhão. Rio de Janeiro: Achiamé, 1981.

BORGES, N. A doutrina de Segurança Nacional e os governos militares. In: FERREIRA, J.; DELGADO, L.A.N. (Orgs.). O Brasil republicano - o tempo da ditadura: regime militar e movimentos sociais em fins do século XX. 3. ed. Rio de Janeiro: Civilização Brasileira, 2009. v. 4.

BOURDIEU, P. Os usos sociais da ciência: por uma sociologia clínica do campo científico. São Paulo: Editora da UNESP, 2004.

BRASIL. Decreto $\mathrm{n}^{\circ}$. 68.065, de 14 de janeiro de 1971. Regulamenta o Decreto-lei $\mathrm{n}^{\circ}$. 869, de 12 de setembro de 1969, que dispóe sobre a inclusáo da Educação Moral e Cívica como disciplina obrigatória, nas escolas de todos os graus e modalidades dos sistemas de ensino no País, e dá outras providências. 1971a. Disponível em $\leq$ http://www2. camara.leg.br/legin/fed/decret/1970-1979/decreto-68065-14-janeiro-1971-409991publicacaooriginal-1-pe.html>. Acesso em: 18 nov. 2016.

BRASIL. Decreto-Lei no ${ }^{\circ}$ 869, de 12 de setembro de 1969. Dispóe sobre a inclusão da Educação Moral e Cívica como disciplina obrigatória, nas escolas de todos os graus e modalidades, dos sistemas de ensino no País, e dá outras providências. 1969. Disponível em <http://www2.camara.leg.br/legin/fed/declei/1960-1969/decreto-lei-869-12-setembro1969-375468-publicacaooriginal-1-pe.html>. Acesso em: 18 nov. 2016.

BRASIL. Parecer no. 94 do CFE, 4 de fevereiro de 1971. Normatiza o ensino e o programa da disciplina de EMC. 1971b. Disponível em: BRASIL. Processo no 681 da UERJ, de 14 de março de 1972.

BRASIL. Processo no 681 da UERJ, de 14 de março de 1972. Relatório de Referência do

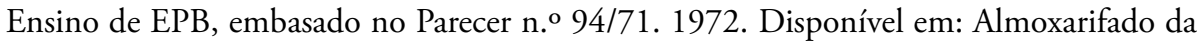
Universidade do Estado do Rio de Janeiro.

CAMARGO, E.J.C. Estudo de problemas brasileiros. Rio de Janeiro: Biblioteca do Exército, 1979.

CANCIAN, R. Movimento estudantil e repressão política: ato público na Pontifícia Universidade Católica de São Paulo (1977) e o destino de uma geração de estudantes. São Carlos: EDUFSCar, 2010.

CUNHA, L.A. A laicidade em xeque: religião, moral e civismo na educação brasileira 1931/97. 2009. Disponível em: <http://www.nepp-dh.ufrj.br/ole/textos equipe2.html>. Acesso em: 6 jun. 2016.

A universidade reformanda: o golpe de 1964 e a modernização do ensino superior. 2. ed. São Paulo: UNESP, 2007a.

- Ambiguidade ideológica na universidade: os estudos de problemas brasileiros. Revista do Centro de Filosofia e Ciências Humanas/CFCH, Rio de Janeiro, ano 1, n. 1, 2010.

Os estudos de problemas brasileiros na UFRJ: aproximaçôes institucionais. Revista Contemporânea de Educação, Rio de Janeiro, v. 7, n. 13, 2012. 
Sintonia oscilante: religiáo, moral e civismo no Brasil - 1931/1997. Cadernos de Pesquisa, São Paulo, v. 37, n. 131, maio/agosto 2007b.

ESCOLA SUPERIOR DE GUERRA, D2-74, Plano Geral de Estudos para o Ano Letivo de 1974. Departamento de Estudos, 1974. Disponível em: Arquivo da Escola Superior de Guerra.

ESCOLA SUPERIOR DE GUERRA, D4-123-72, Programa do 2o Período do Ano Letivo de 1972. Departamento de Alunos, 1972. Disponível em: Arquivo da Escola Superior de Guerra.

ESCOLA SUPERIOR DE GUERRA, Regulamento da Escola Superior de Guerra, 1973. Disponível em: Arquivo da Escola Superior de Guerra.

FILGUEIRAS, J.M. A Educação Moral e Cívica e sua produção didática: 1969-1993. 2006. Dissertação (Mestrado). Departamento de Educaçáo. Pontifícia Universidade Católica, São Paulo.

HAYASHI, M.C.P.I.; VICINO, M.L. Movimento estudantil: história e memória do Centro Acadêmico Armando de Salles Oliveira (CAASO). São Carlos: EDUFSCar, 2007. (Coleção Nova História.)

JOSGRILBERT, M.F.V. A história da Educação Moral e Cívica: um álbum de fotografias da sociedade brasileira. 1998. Dissertação (Mestrado). Programa de Pós-Graduação em Educaçáo. Universidade Federal de Mato Grosso do Sul, Campo Grande.

LEMOS, K.S.C. A normatização da Educação Moral e Civica (1961-1993). 2011. Dissertação (Mestrado). Faculdade de Educação. Universidade Federal do Rio de Janeiro, Rio de Janeiro.

MANCEBO-LERNER, S.L.T. A pós-graduação em estudos de problemas brasileiros na UERJ: uma reflexâo sociológica sobre um projeto de socialização política no Brasil. 2013. Tese (Doutorado). Instituto de Ciências Sociais. Universidade do Estado do Rio de Janeiro, Rio de Janeiro.

MOTTA, R.P.S. As universidades e o regime militar: cultura política brasileira e modernização autoritária. Rio de Janeiro: Zahar, 2014.

. Em guarda contra o "perigo vermelho": o anticomunismo no Brasil (1917-1964). São Paulo: Perspectiva/FAPESP, 2002.

OLIVEIRA, M.A.B. Política e educação no Brasil: a implantação da obrigatoriedade da Educação Moral e Cívica no ensino brasileiro em 1969. 1982. Dissertação (Mestrado em Educação). Faculdade de Educação. Universidade de São Paulo, São Paulo.

SANTOS, E.R. Poder e dominação no Brasil: a Escola Superior de Guerra (1974-1989). Porto Alegre: Sulina; Novo Amburgo: Feevale, 2010.

SEPÚLVEDA, J.A.M. O papel da Escola Superior de Guerra na projeçâo do campo militar sobre o campo educacional. 2010. Tese (Doutorado). Faculdade de Educação. Universidade Federal do Rio de Janeiro, Rio de Janeiro.

Recebido em 8 de julho de 2016.

Aprovado em 19 de outubro de 2016. 